Correspondence

S Kirk

National Primary Care

Research and

Development Centre

University of Manchester

The Williamson Building

Oxford Road

Manchester

M13 9PL

UK

Child: Care, Health and

Development

VOLUME 24

NUMBER 2

1998

PAGES IOI-II4

\section{Families' experiences of caring at home for a technology-dependent child: a review of the literature}

\section{S Kirk}

National Primary Care Research and Development Centre, University of Manchester, UK

Accepted for publication 28 July 1997

\section{Summary}

Recent medical advances have led to the emergence of a group of chronically ill children who are dependent upon technology for their survival. Many of these children are cared for at home by their parents. This paper presents an overview of the literature that has examined the experiences of families caring for a technology-dependent child at home. The social, emotional and financial impact on families and their perspectives on the services supporting them at home is described. The paper concludes by identifying areas where further research is needed.

Keywords: chronic illness, disability, families' experiences, home care, medical technology, service provision

\section{Introduction}

Advances in medical technology have enabled increasing numbers of both preterm infants and infants with congenital impairments to survive. Similarly, medical advances have enhanced the prognosis for children with chronic illnesses and cancer (Woodrooffe et al. 1993; Bradley et al. I995; Draper 1995). One consequence of such advances is that there now exists a group of children with continuing medical and nursing needs, some of whom remain dependent on the very technology that enabled them to survive. This extension to the disabled and chronically ill child population has been accompanied by a move to care for such children at home rather than in hospital. This has occurred as a response to policies emphasizing the community as the arena for care for people with high levels of social and physical disabilities in general (DoH I989) and for sick children in particular (DoH I99I, I996). The result of such policies is that complex nursing care, involving sometimes highly technical procedures, is now 
Kirk • Families' experiences of caring at home for a technology-dependent child

being carried out in the home environment, frequently by parents. This paper will present an overview of the research-based literature that explores the impact on the family of caring for children who are dependent on technology.

\section{Who are technology-dependent children?}

Technology-dependent children can be viewed as a small subset of the chronically ill and disabled child population, but set apart by both the level and the nature of the care they require. The term 'technology-dependent' is used in the literature to describe children

'who need both a medical device to compensate for the loss of a vital body function and substantial and ongoing nursing care to avert death or further disability'

(Wagner et al. I988: p. 3)

This group of children are dependent on a device or technology which is lifesustaining and their dependence upon it is assumed to be prolonged. Many technology-dependent children are dependent upon more than one device (Beresford 1995). A key characteristic is their need for substantial and ongoing nursing care provided by either a trained nurse or a lay caregiver (Wagner et al. I988). This care is often of a highly technical nature and is required for large parts of the day and often the night. The types of technologies or devices on which children may be dependent ranges from the 'high-tech' (for example, a mechanical ventilator) to the relatively 'low- tech' (for example, a colostomy) (Table I). The majority of studies that explore the needs of this group of children and their families focus on those with a dependence on 'high-tech' medical technologies. Children who may require a substantial amount of care but minimal equipment, such as those with diabetes, epilepsy, or asthma, do not tend to be encompassed by the term in the literature.

Technology-dependent children are a diverse group, even aside from the technology on which they are dependent. The cause of the dependency itself varies. It can be the result of a congenital condition, a chronic illness or genetic condition. It may be associated with prematurity or have occurred following an

Child: Care, Health and Development

VOLUME 24

NUMBER 2

1998

PAGES IOI-II4 accident, infection or illness. Indeed, a wide range of medical conditions, affecting most systems of the body, may lead to technology-dependence. Technology-dependent children also differ in terms of the age at which they became technology-dependent, their level of disability, whether the dependence is continuous or intermittent and whether the dependence is permanent or temporary. 
Kirk - Families' experiences of caring at home for a technology-dependent child

Table I. Types of technologies on which children may be dependent

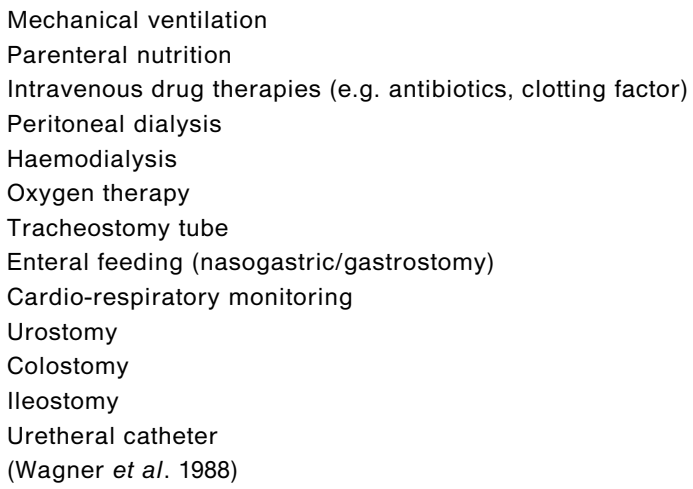

\section{Prevalence of technology-dependent children}

It is difficult to determine the precise number of children who are dependent upon technology, and this will, in any case, vary according to the criteria used to define technology-dependence. In the USA in I988 it was estimated that there were up to I00 000 children dependent upon medical technology and it is highly likely that this population has increased since that time (Wagner et al. 1988). Indeed, Palfrey et al. (1994) discovered that there had been a $42 \%$ increase in the size of the technology-dependent children population in Massachusetts between 1987 and 1990. Although the size of the technology-dependent children population in the UK is unknown, a recent national survey revealed that $43 \%$ of severely disabled children under the age of 2 years were dependent upon medical technology (Beresford 1995). Some attempts have been made in the UK to estimate the incidence and prevalence of children dependent on specific technologies (Jennings 1990; Robinson 1990). However, the low response rates reported cast doubt on the accuracy of these figures. Research is currently in progress at Great Ormond Street Hospital which will provide information on the number of children being cared for at home in the UK who are dependent upon mechanical ventilation.

Child: Care, Health and

Development

VOLUME 24

NUMBER 2

I998

PAGES IOI-II4

\section{North American perspectives}

The vast majority of the existing literature on the home care of technologydependent children is North American, reflecting the emergence of the group there in the I980s following changes in federal health care reimbursement 
policies. These changes allowed states to waive certain Medicaid eligibility rules and provide intensive home care services for technology-dependent children (Okun 1995). In the United States, caring for this group of children at home has been promoted on the basis that it relieves families from the disruption and the financial costs associated with hospital visiting and has the potential to give parents an increased sense of control over their child's care (Hazlett 1989; Smith 1991; Lewis et al. 1992). There are also suggestions that the technologydependent child's quality of life, physical functioning and overall development may improve as a direct result of being cared for in the home (Burr et al. 1983; Schreiner et al. 1987; Donar 1988; Aday et al. 1989; Wong 1991; Lewis et al. 1992). The reasons for such improvements are thought to be the continuity of care the child receives in the home (Smith 199I) and its more nurturing environment (Wong I991).

In addition, evidence suggesting that health care costs could be reduced by caring for technology-dependent children at home has proved to be attractive to insurance companies and has provided another motivating factor in the growth of home care in the US (Burr et al. 1983; Lynch 1990; Fields et al. 1991). However, it is unclear if costs are reduced in reality. Concerns have been expressed that such studies are methodologically flawed due to the difficulties in comparing equivalent costs in the hospital and home and due to their neglect of the financial, social and emotional costs incurred by the families themselves (Bakewell-Sachs \& Porth 1995). Aday et al. (1989) in their evaluation of three home care services for ventilator-dependent children discovered that although costs were reduced, most of the savings came from the substitution of parental for professional nursing care and from the decreased number of laboratory investigations carried out when children are cared for at home. They conclude that the greater the extent of professional nursing in the home the lower the cost savings but the higher the cost to parents in terms of the stress they experience.

Child: Care, Health and Development

VOLUME 24

NUMBER 2

1998

PAGES IOI-II4

\section{Family perspectives and experiences}

Professionals in the UK have written about their concerns over the considerable burdens being placed on parents when they care for technology-dependent children at home (David 1989; Bisset et al. 1992; Watson 1995; Holden \& Kelcey 1997) as have representatives from the voluntary sector (McAffrey I992). Issues surrounding the financial costs and the ethics of caring for a ventilator-dependent child at home have also been debated recently in the British Medical fournal (Davies 1996; Harvey I996; Newton-John I996; Ward 
I996). However, there is a lack of published research that has investigated parents' experiences of caring for a technology-dependent child in the UK. One study which has explored parents' perspectives is that of Jennings (I990) who conducted a small scale in-depth study of mothers caring for a child with a tracheostomy. The findings from this study will be reported later in the paper. Due to a lack of UK research-based literature, this paper draws largely on North American studies to describe the experiences of parents caring for a technologydependent child at home.

\section{The social impact on the family}

It is well documented in the literature that caring for a child who is technologydependent can be socially isolating for parents. Family activities can be severely restricted which may lead to them becoming virtually house-bound (Andrews \& Nielson 1988; Young et al. 1988; Aday et al. 1989; Diehl et al. 1991; McKeever I99I; Teague et al. I993; Patterson et al. I994; Bradley et al. I995; Clarke 1995). This social isolation can be a result of the unwieldy nature of the equipment the child needs, which makes leaving the house a major expedition or because of the parents' sense of utter exhaustion. Finding baby-sitters who are willing and able to care for a child with such specialized needs is problematic and parents are in any case often afraid to leave their child in the care of others. There is evidence that after the initial period home after discharge from hospital, support from families and friends tends to decrease (Andrews \& Nielson 1988).

Social isolation has been reported in studies examining the experiences of the parents of disabled children in general (Baldwin \& Carlisle 1994) but two additional problems which this particular subgroup may face are firstly, changes to the home environment as a result of the transfer of technology into the home and secondly, a loss of privacy. Major modifications of the home may be required to enable the child to be cared for at home (Bradley et al. I995). The impact on the home milieu can be dramatic as it may well be transformed by equipment and personnel into an environment associated more with a hospital intensive care unit (Smith I99I). The home hence loses its personal association

Child: Care, Health and Development

VOLUME 24

NUMBER 2

1998

PAGES IOI-II4 with comfort, security and privacy (Arras \& Dubler 1995) and daily life becomes dominated and routinized by the procedures relating to the technologydependence (McKeever I99I). In addition this group of families often require a considerable amount of service support on a daily basis, with some families receiving home nursing services for up to $24 \mathrm{~h}$ a day (Quint et al. I990; Leonard et al. 1993). Inevitably, this leads to a loss of privacy for families (Aday et al. 
1989; Scharer \& Dixon 1989; Leonard et al. 1993; Clarke 1995). Family life occurs in public, under the gaze of the various nurses and therapists who visit or spend long periods of time in the home. Arguments among family members occur within the sight or sound of the professionals in the home and demonstrations of affection are inhibited. This provides parents with a dilemma; they need both the support of professionals and their own privacy, but the two are incompatible (Feinberg 1985).

\section{The emotional impact on the family}

When a technology-dependent child is discharged from hospital it may well be the first time that $\mathrm{s} / \mathrm{he}$ has gone home since birth. Consequently, the family have to commence the process of integrating a new family member, and one with considerable needs, several months or even years after her/his birth. It is perhaps not surprising that the adaptation process may be problematic for families (Smith I99I).

A consistent theme in the literature are parent's reports of sleep deprivation due to anxiety about the child's condition, false monitor alarms or the need to remain vigilant over their child during the night (Andrews \& Nielson 1988; Aday et al. 1989; Scharer \& Dixon 1989; McKeever 1991; Teague et al. 1993; Clarke 1995). Parents can feel overburdened with the responsibilities and the continuing care demands placed upon them (Andrews \& Nielson I988; Aday et al. 1989). Quint et al. (1990) in a small scale study found that those parents who had been caring for their technology-dependent child for more than 2 years had lower coping scores and were literally burnt out and exhausted. In Jenning's (1990) in-depth study of Io mothers caring for a child with a tracheostomy at home the mothers reported that they found the experience exhausting and sometimes overwhelming. They expressed the fear of not hearing the child if he/she was in trouble and dreaded waking up and finding them dead. This fear of them dying whilst in their care was ever-present. The mothers in McKeever's (199I) study similarly described themselves as being constantly on alert for a crisis. The uncertainty of the chronic illness and the child's prognosis can be a further source of anxiety for parents (Andrews \&

Child: Care, Health and Development

VOLUME 24

NUMBER 2

1998

PAGES IOI-II4 Nielson 1988; Patterson et al. 1994) and such concerns can be compounded by concerns over the child's long-term development and education (Aday et al. I989).

The literature documents a wide range of emotions experienced by parents, such as anxiety, anger, guilt, and frustration (Andrews \& Nielson 1988; Smith et al. I991; Patterson et al. 1994). A number of studies have found evidence of 
mental health problems amongst the caregivers, such as depression, which in some cases warranted psychiatric intervention (Smith et al. I991; Leonard et al. I993; Teague et al. 1993; Patterson et al. 1994). One major source of anxiety is the nature of the care this group of parents provide, such as suctioning airways and giving injections. The type of procedures they perform are not only potentially dangerous but they may also involve parents inflicting pain on their child, something which is in direct conflict with a parent's natural desire to protect (Jennings I990; McKeever I99I).

Some studies have reported an increased number of family illness symptoms (Patterson et al. 1992), family stress (Leonard et al. 1993; Teague et al. 1993) reduced family functioning (Diehl et al. I99I) and behavioural changes in siblings (Smith I99I). The impact on intrafamilial relationships can be considerable. There are reports of profound difficulties in mothers' relationships with their other children (Jennings 1990) and a number of studies have discovered the presence of marital problems (Andrews \& Nielson I988; Jennings I990; Teague et al. I993; Petr et al. 1995).

A number of studies have investigated whether the level of stress experienced relates to demographic or other differences between parents caring for technology-dependent children. The research suggests that caregiver stress can be related to financial problems (Wegener \& Aday I989; Teague et al. I993; Fleming et al. 1994), overall levels of family responsibilities (such as situations where both parents work outside the home or where there are other children) (Leonard et al. 1993), and to the type and the amount of home care services the family receive (Leonard et al. (1993). In relation to the latter, Leonard et al. I993) found that professional workers who can provide direct care for the child were more effective in relieving stress than those whose role was limited to performing housework tasks.

Wegener and Aday (1989) discovered that the predictors of family stress were financial problems, families who had large number of extended family members in same house, where the child had been recently discharged from hospital, where there were large numbers of doctors involved in care and where there was no nurse care manager. Financial problems were found to be the most powerful predictor of family stress.

Child: Care, Health and

Development

VOLUME 24

NUMBER 2

1998

PAGES IOI-II4

\section{The financial impact on the family}

Parents in the US experience difficulties coping with the complex eligibility criteria and service restrictions associated with the organization and funding of the health care system (Petr, Murdock \& Chapin 1995). Health insurance or 
other financing mechanisms may not be sufficiently comprehensive to cover all the costs of care, leaving families to find the money for essential aspects of their child's care themselves (Aday et al. 1989).

The existence of financial problems has been noted in a number of studies (Andrews \& Nielson 1988; Wegener \& Aday I989; McKeever I99I; Diehl et al. I99I; Youngblut et al. 1994), with Aday et al. (1989) discovering that $40 \%$ of the families in their study were experiencing serious financial problems. Mothers often have to leave employment, which reduces family income at a time when the financial costs of caring arise because of expenses such as increased electricity and water bills or long-distance travel to specialist centres (Feinberg 1985; Wheeler \& Lewis 1993). Not surprisingly, as noted in the previous section, their financial position has been identified as source of anxiety and stress for families with technologydependent children (Teague et al. I993; Patterson et al. I994; Youngblut et al. 1994).

\section{Views and experiences of support services}

\section{Obtaining appropriate care: competency and availability}

A number of studies document how the parents themselves have to be advocates for their child. This leads to them constantly having to assert their rights in order to receive appropriate care, something which is both timeconsuming and stressful for parents who may already be overburdened and exhausted (Diehl et al. I99I; McKeever I99I; Petr et al. 1995).

The type and the amount of support parents receive from home care services in the US would seem to be variable and largely dependent upon how the care is being funded (Stutts 1994). In one study the type and amount of home care families received varied according to the particular insurance policy and could range from $24 \mathrm{~h}$ professional nursing care, through support from untrained home care workers, to no paid care at all (Leonard et al. 1993). An evaluation by Aday et al. (1989) of three home care programmes for ventilator-dependent children also found wide variations in

Child: Care, Health and Development

VOLUME 24

NUMBER 2

1998

PAGES IOI-II4 nursing support, with the average input being $\mathrm{I} 3 \mathrm{~h}$ of professional nursing care per day. They discovered that those families receiving less than $32 \mathrm{~h}$ of home nursing per week were more likely to feel overburdened and socially isolated. In a study by Quint et al. (1990) although the majority of families received an average of $9 \mathrm{~h}$ of home nursing support per day, $17 \%$ of families had no form of home nursing support at all. Maintaining adequate home 
care over time can also be problematic for parents. The mothers in McKeever's (I99I) study reported having to contend with a continual threat of service withdrawal.

Many studies highlight parents' concerns over the competency of the nursing staff who are available to support them in caring for their child at home (Young et al. I988; Aday et al. I989; Jennings 1990). Community-based professionals, even trained paediatric nurses, can be perceived as being unfamiliar with the specialized needs of technology-dependent children and the equipment on which they depend (Young et al. 1988; Wheeler \& Lewis 1993). In the only published UK study, mothers felt inadequately supported by generic community nurses such as health visitors and district nurses, who were perceived as lacking the specialist knowledge with which to support the family in caring for a child with a tracheostomy (Jennings 1990). It can be problematic to find suitably qualified nurses to provide care outside normal working hours, such as nights and weekends (Petr et al. 1995). Access to trained children's nurses (and other home care services) can also be a particular problem in rural areas (Wheeler \& Lewis I993).

There are reports of services being fragmented, duplicated and poorly coordinated, particularly between the community and specialist centres (Young et al. I988; Diehl et al. I99I; Wheeler \& Lewis I993). Families may lack a designated care manager (Aday et al. 1989) which can lead to parents spending vast amounts of time co-ordinating services themselves (McKeever I99I). There is evidence of confusion over medical responsibility with parents being unclear whether the primary care physician (general practitioner) or specialist is responsible for their child's care (Wheeler \& Lewis I993). Similarly, in a UK study parents did not know when to approach their general practitioner and when to contact the hospital directly (Jennings I990). The hospital discharge process can also be poorly planned and organized (Young et al. 1988; Jennings 1990), with delays experienced in the receipt of services in the home.

Obtaining the equipment required and the services to support its use in the home can be problematic (Andrews \& Nielson 1988; Aday et al. I989; Quint et al. 1989; Jennings 1990). Parents can experience problems in the

Child: Care, Health and Development

VOLUME 24

NUMBER 2

1998

PAGES IOI-II4 maintenance of equipment, in dealing with equipment breakdowns, and with the collection and delivery of supplies.

In relation to education services, there are reports of parents experiencing problems in getting their child's needs assessed (Diehl et al. I99I), with transportation to school and with the educational provision for children with such specialized needs (Wheeler \& Lewis I993). 
Kirk - Families' experiences of caring at home for a technology-dependent child

\section{Obtaining a break from caring}

A consistent theme in the literature is the problems parents face in obtaining a break from caring for their technology-dependent child. Many studies report difficulties in gaining access to short-term/respite care (Diehl et al. I99I; Wheeler \& Lewis 1993; Youngblut et al. 1994; Petr et al. 1995). Finding babysitters for an evening out or other leisure activities can be equally problematic (Young et al. 1988; McKeever I99I; Teague et al. 1993) because of the child's specialized nursing needs and the lack of either professional or non-professional care-givers to provide home-based short-term/respite care. Even those parents who do manage to obtain short-term care are reported to be concerned over its quality (Aday et al. 1989; Diehl et al. 1991), with many parents noting that services are designed for those with developmental rather than complex physical care needs (Wheeler \& Lewis 1993).

\section{Information-giving}

A number of studies have found that parents can feel inadequately prepared for performing the highly technical procedures their child needs and in the use of the equipment on which they are dependent (Andrews \& Nielson I988; Diehl et al. I99I). In Jenning's (I990) study of mothers caring for a child with a tracheostomy at home, a number of mothers remarked that several people were involved in training them but no single person co-ordinated the teaching. Mothers were often the only person taught the technical procedures and in one case the mother was only shown how to change the tracheostomy tube on the day of discharge. The mothers interviewed were clearly anxious about the procedure they would need to perform at home, which was both painful to the child and was potentially life-threatening. Hospital staff were reported to assume both that families would feel prepared to take their child home and that they could cope with the technical care needed.

Child: Care, Health and Development

VOLUME 24

NUMBER 2

1998

PAGES IOI-II4

\section{Parent-professional relationships}

A number of studies note the existence of problematic relationships between parents and professionals in relation to issues such as control, trust and competence (Young et al. I988; Aday et al. I989; Scharer \& Dixon I989; Diehl et al. I99I; McKeever I99I). As McKeever (I99I) has noted, this group of parents experience contradictory expectations as they are asked to become 
sophisticated health care experts and have responsibility for their child's care but at the same time they are still expected to defer to, and comply with, the advice they receive from professionals. The mothers in McKeever's study were found to move over time from a compliant to an assertive role as they gained knowledge and confidence in caring for their child and experience in their encounters with health professionals. In response to this move, professionals adopted counter-resistant strategies such as avoiding contact with the mothers or using psychological pressure in an attempt to coerce them into complying with professional advice.

In a study focusing on parent-professional relationships, Patterson et al. (1994) found that professionals who were willing to collaborate and who recognized the competence and skill of parents were the key factors in positive parent-professional relationships. Other important factors leading to positive parent-professional relationships were professionals who genuinely cared for the child and who had respect for the family. Conversely, factors contributing to a poor relationship were invasion of privacy, unprofessional and inadequately trained staff, lack of respect, cancellation of visits and high staff turnover.

\section{Conclusions}

The nature of the disabled and chronically ill child population is changing as a result of medical advances and now includes a group of children who are dependent on technology for their survival. The research reviewed reveals that there are similarities in the experiences of parents caring for a technologydependent child and parents caring for a disabled child. Social isolation, exhaustion, stress, financial and marital problems, problematic relationships with professionals and poorly co-ordinated services have all been reported in studies focusing on the parents of disabled children (Glendinning 1983; Sloper \& Turner 1992; Baldwin \& Carlisle 1994; Beresford 1994). However, it is also apparent that the experience of caring for a technology-dependent child is different as a result of the child's intensive and complex health care needs. The transformation of the home environment by the technology, the loss of privacy, and the need to perform highly technical procedures are some of the ways in

Child: Care, Health and Development

VOLUME 24

NUMBER 2

1998

PAGES IOI-II4 which caring for a technology-dependent child differs from caring for a disabled child. There are also specific problems in relation to service provision, such as obtaining respite care that is appropriate for the needs of technology-dependent children and developing supportive parent-professional relationships that recognize the parent's expertise in providing specialized nursing care.

At present very little is known about the experience of caring for a 
Kirk • Families' experiences of caring at home for a technology-dependent child

technology-dependent child in a UK context. There is therefore an urgent need for research to explore the experiences and perspectives of both the parents and the children themselves. It is important that the potential benefits of home care such as continuity of care, increased parental control and reduced health care costs are not outweighed by the costs borne by families such as stress and financial problems. There is also a need to examine how services for families who are caring for children with very complex needs are provided and coordinated, particularly since the creation of quasi-markets in health and social care and the development of local continuing care policies.

\section{Acknowledgements}

The views expressed in this paper are those of the author and not those of the Department of Health. The author would like to thank Caroline Glendinning for her comments on earlier drafts of the paper and Steve Rose for his assistance with the literature search.

\section{References}

Aday, L. A., Wegener, D.H., Anderson, R. \& Aitkin, M. (I989) Home care for ventilator assisted children. Health Affairs, 8, I37-147.

Andrews, M. M. \& Nielson, D. W. (1988) Technology dependent children in the home. Pediatric Nursing 14, I I I-I I4, I5I.

Arras, J. \& Dubler, N. (I995) Ethical and social implications of high-tech home care IN Arras, J (Ed) Bringing the hospital home. John Hopkins University Press, Baltimore.

Bakewell-Sachs, S. \& Porth, S. (1995) Discharge planning and home care of the technologydependent infant. Fournal of Obstetric, Gynaecological and Neonatal Nursing, 24, 77-83.

Baldwin, S. \& Carlisle, J. (1994) Social support for disabled children and their families: a review of the literature. HMSO, London.

Beresford, B. (I994) Positively parents: caring for a severely disabled child. Social Policy Research Unit, University of York, York.

Beresford, B. (1995) Expert Opinions: a national survey of parents caring for a severely disabled child. Policy Press, Bristol.

Bissett, W. M., Stapleford, P., Long, S. et al. (I992) Home parenteral nutrition in chronic intestinal failure. Archives of Disease in Childhood, 67, I09-II4.

Child: Care, Health and

Development

VOLUME 24

NUMBER 2

1998

PAGES IOI-II4
Bradley, R. H., Parette, H. P. \& Van Bierliet, A. (I995) Families of young technology-dependent children and the social worker. Social Work in Pediatrics, 21, 23-37.

Burr, B. H., Guyer, B., Todres, I., Abrams, B. \& Chiodo, T. (I983) Home care for children on respirators. New England fournal of Medicine, 309, I319-1323.

Clarke, J. E. (1995) Rural home care of a technology-dependent infant. Canadian Family Physician, 4I, I05I-I056. 
Kirk • Families' experiences of caring at home for a technology-dependent child

David, T. J. (1989) Intravenous antibiotics at home in children with cystic fibrosis. Fournal of the Royal Society of Medicine, 82, I30-I3I.

Davies, R. H. (1996) Home ventilation of a child with motor and sensory neuropathy. British Medical fournal, 313, I53-I54.

Department of Health (1989) Caring for People: Community care in the next decade and beyond. HMSO, London.

Department of Health (I99I) Welfare of children and young people in hospital. HMSO, London.

Department of Health (1996) Child Health in the Community: a guide to good practice. Department of Health London.

Diehl, S., Moffitt, K. \& Wade, S. M. (I99I) Focus group interviews with parents of children with medically complex needs: an intimate look at their perceptions and feelings. Children's Health Care, 20, I70-I78.

Donar, M. (1988) Community care: pediatric home mechanical ventilation. Holistic Nursing Practice, 2, 68-80.

Draper, G. (I995) Cancer. In Botting, B (Ed) The health of our children: decennial. (Suppl.) Office for Population Censuses and Surveys, London.

Feinberg, E. (1985) Family stress in pediatric home care. Caring, 38, 40-4I.

Fields, A., Rosenblatt, A., Pollack, M. \& Kaufman, J. (I99I) Home care cost-effectiveness for respiratory technology-dependent children. American fournal of Disease in Children, 145, 729-733.

Fleming, J., Chalella, M., Eland, J. et al. (I994) Impact on the family of children who are technology dependent and cared for in the home. Pediatric Nursing, 20, 379-388.

Glendinning, C. (1983) Unshared care: parents and their disabled children. Routledge Paul, London.

Harvey, I. (1996) Commentary: Reach beyond metaphor to assess value. British Medical fournal, 313, I54.

Hazlett, D. E. (1989) A study of pediatric home ventilator management: medical, psycho-social and financial aspects. Fournal of Pediatric Nursing, 4, 284-294.

Holden, C. \& Kelcey, H. (I997) Fluid systems. Nursing Times, 93, 6I-64.

Jennings, P. (1990) Caring for a child with a tracheostomy. Nursing Standard, 4 (30), 24-26 and 4 (32), 38-40.

Leonard, B., Brust, J. D. \& Nelson, R. (I993) Parental distress: caring for medically fragile children. Fournal of Pediatric Nursing, 8, 22-30.

Lewis, C., Alford-Winston, A., Billy-Kornas, M., McCaustland, M. D. \& Tachman, C. P. (I992) Care management for children who medically tragile/technology-dependent. Issues in Comprehensive Paediatric Nursing, 15, 73-91.

Lynch, M. (I990) Home care of the ventilator-dependent child. Children's Health Care, 19, I69I73.

McAffrey, M. (1992) High tech care at home. Carelink Winter, 2.

McKeever, P. (I99I) Mothering chronically-ill technology-dependent children: an analysis using critical theory. $\mathrm{PhD}$ thesis, York University, Canada.

Child: Care, Health and Development

VOLUME 24

NUMBER 2

1998

PAGES IOI-II4
Newton-John, H. (1996) Commentary: Little real choice. British Medical fournal, 313, I55.

Okun, A. (1995) The history of respirators and total parentereal nutrition in the home and their use in children today. In Arras, J. (Ed) Bringing the hospital home. John Hopkins University Press, Baltimore.

Palfrey, J. S., Haynie, M., Porter, S. et al. (I994) Prevalence of medical technology assistance among children in Massachusetts in 1987 and 1990. Public Health Reports, 109, 226-233. 
Kirk • Families' experiences of caring at home for a technology-dependent child

Patterson, J., Jernell, J., Leonard, B. \& Titus, J. C. (1994) Caring for medically fragile children at home: the parent professional relationship. Fournal of Pediatric Nursing, 9, 98-106.

Petr, C. G., Murdock, B. \& Chapin, R. (1995) Home care for children dependent on medical technology: the family perspective. Social Work in Health Care, 2I, 5-22.

Quint, R. D, Chesterman, E., Crain, L., Winkleby, M. \& Boyce, T. (I990) Home care for ventilator dependent children. American fournal of Diseases in Children, 144, I238-124I.

Robinson, R. O. (1990) Ventilator dependency in the United Kingdom. Archives of Disease in Childhood, 65, I235-1236.

Scharer, K. \& Dixon, D. (I989) Managing chronic illness: parents with a ventilator dependent child. Fournal of Pediatric Nursing, 4, 236-247.

Schreiner, M. S., Dona, M. \& Kerrick, R. (1987) Pediatric home mechanical ventilation. Pediatric Clinics of North America, 34, 47-6o.

Sloper, P. \& Turner, S. (I992) Service needs of families of children with severe physical disability. Child: Care, Health and Development, 18, 259-282.

Smith, S. J. (I99I) Promoting family adaptation to the home care of the technology-dependent child. Issues in Comprehensive Paediatric Nursing, 14, 249-258.

Smith, C., Giefer, D. \& Bieker, L. (I99I) Technology-dependency: a preliminary model and pilot of home total parenteral nutrition. Fournal of Community Health Nursing, 8, 245-254.

Stutts, A. (1994) Selected outcomes of technology dependent children receiving home care and prescribed child care services. Pediatric Nursing, 20, 50 I-507.

Teague, B. R., Fleming, J., Castle, A. et al. (I993) High tech home care for children with chronic health conditions: a pilot study. Fournal of Pediatric Nursing, 8, 226-232.

Wagner, J., Power, E. J. \& Fox, H. (1988) Technology-dependent children: hospital versus home care. Office of Technology Assessment Task Force, J.P Lippincott, Philadelphia.

Ward, T. (1996) Commentary: Need for for a nationally consistent approach. British Medical fournal, 313, I55.

Watson, A. (1995) Strategies to support families of children with end-stage renal failure. Pediatric Nephrology, 9, 628-631.

Wegener, D. H. \& Aday, L. A. (I989) Home care for ventilator assisted children: predicting family stress. Pediatric Nursing, 15, 371-376.

Wheeler, T. \& Lewis, C. C. (I993) Home care for medically fragile children: urban versus rural settings. Issues in Comprehensive Paediatric Nursing, 16, I3-30.

Wong, D. L. (I99I) Transition from hospital to home for children with complex medical care. Fournal of Pediatric Oncology Nursing, 8, 3-9.

Woodroffe, C., Glickman, M., Barker, M. \& Power, C. (I993) Children, teenagers and health: the key data. Open University Press, Buckingham.

Young, L., Creighton, D. \& Sauve, R. (1988) The needs of families of infants discharged home with continuous oxygen therapy. Fournal of Obstetric, Gynaecological and Neonatal Nursing, 17, I87-I93.

Child: Care, Health and Development

VOLUME 24

NUMBER 2

1998

PAGES IOI-II4
Youngblut, J., Brennan, P. \& Swegart, L. (1994) Families with medically fragile children: an exploratory study. Pediatric Nursing, 2o, 463-468. 